\title{
NEWS
}

\section{Chemical-safety costs uncertain}

Researchers and regulators disagree on how REACH legislation will affect costs and loss of animal lives.

Europe's chemical regulator has questioned a study suggesting that industry will have to spend $€ 9.5$ billion (US $\$ 13.6$ billion) - six times more than expected - on toxicity testing over the next decade, to comply with European Union (EU) legislation on chemical safety. The tests would require an estimated 54 million animals - a situation dismissed as a "worst-case scenario" by the European Chemical Industry Council (Cefic), a Brussels-based organization representing the European chemical industry.

The EU's REACH (Registration, Evaluation, Authorisation and Restriction of Chemicals) legislation, which came into force in 2007, is the world's most extensive attempt at improving the safe use of chemicals. It requires the registration and submission of toxicity data for all chemicals sold in the EU in quantities of more than one tonne per year by 2018 .

But a study by Thomas Hartung, former head of the European Centre for the Validation of Alternative Methods (ECVAM) in Ispra, Italy, and Costanza Rovida, a consultant chemist in Varese, Italy, says that Europe lacks enough laboratories to carry out all the tests that the legislation demands. This will render the legislation unfeasible, concludes the study, which will be presented at the World Congress on Alternatives and Animal Use in the Life Sciences in Rome that begins on 30 August.

REACH's aim "will not be achieved" using traditional toxicity testing methods, says Hartung, now at Johns Hopkins University in Baltimore, Maryland. "The problem is that REACH will exceed the test capacities in Europe," he says. "This will cause delays in testing, and [regulators] will not get all the data needed to take the decisions that are necessary."

Hartung calls for a moratorium on the requirement to test chemicals' effects on reproductive systems in two generations of animals. These two-generation studies account for the lion's share of the increase in costs and test animals, the study says. The Organisation for Economic Co-operation and Development (OECD) is drawing up guidance for an extended one-generation reproductive toxicity test. The aim of this scheme is that tests beyond the first generation would be conducted only if a specific cause for concern arose in the first-generation offspring.

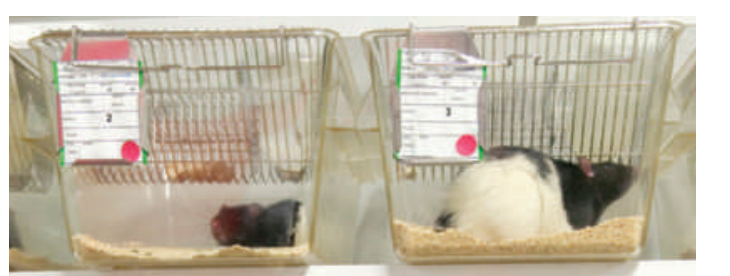

numbers of animals used are based on an expectation that at least 68,000 chemicals will be registered by 2018 , given the growth in the EU's chemical industry over the past 15 years and the addition of 15 more countries to the EU since 1995.

Cefic says it does not think that this growth will result in drastically more substances being registered. The council also expects around 30,000 chemicals to be registered by December 2018. "We are convinced that the situation in the article will not be reached because there will be fewer substances to be registered," says Erwin Annys, the council's director of chemicals policy.

However, Manfred Liebsch, a toxicologist at the Federal Institute for Risk Assessment in Berlin, says the study's figures are "realistic". "I support the aims of REACH, but if there are delays in testing, it will not be doing its job of providing safety to people and the environment," he says. "Something must be changed."

BASF, the chemical company headquartered in Ludwigshafen, Germany, says "it is not able to give valid feedback on the estimated numbers of needed studies and costs yet", because discussions on

The OECD will hold a meeting in October to discuss outstanding technical issues, including what would be considered as a trigger for additional tests. Draft guidelines are expected to be submitted for approval in March 2010. If they get the green light, the guidelines would be published around September 2010, and could then be instituted before testing begins in December 2010.

\section{European enlargement}

In a written response to Nature, the European Chemicals Agency, in Helsinki, which administers the REACH system, disputes many of the figures put forth in the new study. The agency expects slightly more than 9,000 chemicals to be registered under REACH by its 1 December 2010 deadline for substances produced or imported in quantities of more than 1,000 tonnes a year, and 30,000 chemicals by 2018 . It says it does not expect the costs and use of laboratory animals to differ significantly from the original estimates, which were based on an expectation that 8,730 chemicals would be registered by the 2010 deadline.

Hartung says that his estimates of cost and toxicity data are ongoing. "It's not clear yet if all needed animal tests requested by REACH can be finalized in time," the company says. "It seems there is not enough testing capacity available globally."

"The article gives the impression that the data requirements for REACH can only be fulfilled by additional testing. This is not correct. So it is difficult to say how accurate the conclusions are," says Claudius Griesinger, a neuroscientist and project manager at the ECVAM. "Only practice will show what data are currently available."

Hartung calls for increased funding of new toxicology testing methods, saying that alternatives to animals experiments must be found if $\mathrm{REACH}$ is to succeed. He says the biggest advances are currently taking place in the United States, in particular the Environmental Protection Agency's ToxCast programme, which is developing ways to forecast the potential toxicity of chemicals using high-throughput screening bioassays developed in the pharmaceutical industry to discover new drugs.

Natasha Gilbert

See Opinion, page 1080. 